\title{
Memorias del genocidio. Guatemala: masacre, aniquilamiento y sobrevivencia*
}

\author{
Manolo E. Vela Castañeda
}

Ricardo Falla, 2011

Negreaba de zopilotes... Masacre y

sobrevivencia: finca San Francisco, Nentón, Guatemala (1871 a 2010)

Asociación para el Avance de las Ciencias Sociales en Guatemala, Guatemala, 437 pp.
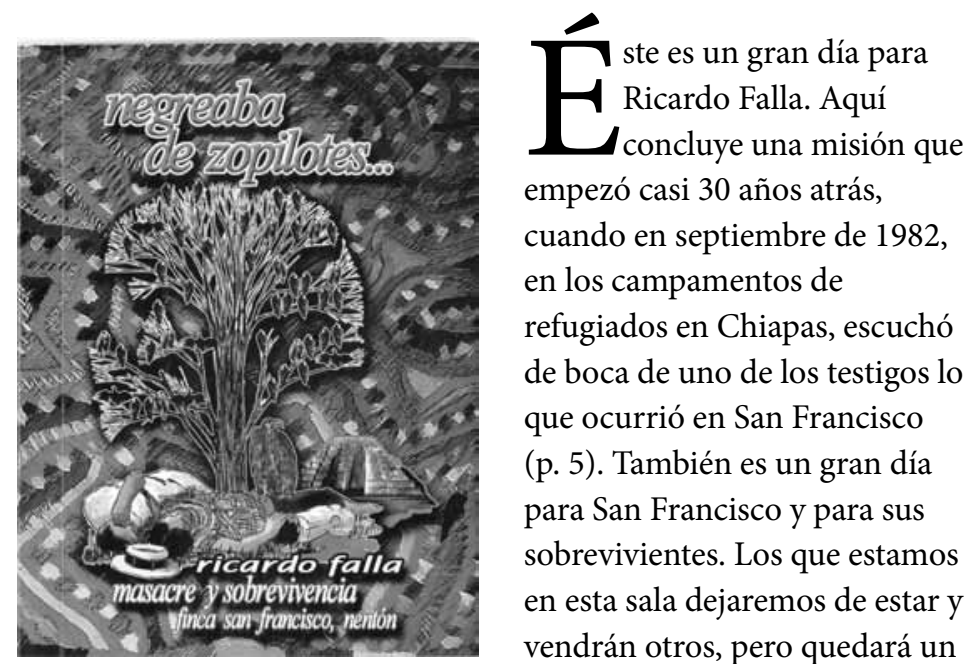
empezó casi 30 años atrás, cuando en septiembre de 1982, en los campamentos de refugiados en Chiapas, escuchó de boca de uno de los testigos lo que ocurrió en San Francisco (p. 5). También es un gran día para San Francisco y para sus sobrevivientes. Los que estamos en esta sala dejaremos de estar y vendrán otros, pero quedará un

Memories of Genocide. Guatemala: Massacre,Annihilation and Survival

Manolo E. Vela Castañeda: Departamento de Ciencias Sociales y Políticas, Universidad Iberoamericana, Distrito Federal, México mevela@colmex.mx

Desacatos, núm. 39, mayo-agosto 2012, pp. 212-217

\footnotetext{
* Texto leído durante la presentación del libro el 12 de abril de 2011 en el Exconvento de Santo Domingo, Salón Mayor “Rigoberta Menchú Tum”, en la ciudad de Guatemala.
}

libro que cuenta la historia de los que murieron en esa tierra, en aquel momento de la historia de Guatemala. En tercer lugar es un gran día para la Asociación para el Avance de las Ciencias Sociales en Guatemala (Avancso) y para su equipo, que este año cumplen 25 años de hacer ciencia social, con todo lo que eso implica en un país como Guatemala. Durante estos años, el equipo de Avancso ha sabido hacer de las grandes limitaciones para la investigación en este país una fuerza que lo ha impulsado a emprender investigaciones serias, llevadas a cabo con rigor intelectual y calidad académica.

Antes de empezar mis comentarios quisiera agradecer al autor lo mucho que le ha dado a Guatemala. Desde hace mucho 
tiempo tomó como misión dar a conocer al mundo el genocidio que tuvo lugar en el país. Sin los trabajos en los que Ricardo Falla ha invertido una parte del tiempo de su vida, sus energías, sus nervios, sus sentimientos, los guatemaltecos sabríamos menos de lo que ahora sabemos. Gracias, Ricardo Falla, por lo que has hecho y gracias por haber escrito este nuevo libro.

El libro empieza

presentándonos los hechos: la masacre del 17 de julio de 1982 en la comunidad chuj de la finca San Francisco, Nentón, Huehuetenango, cometida por tropas del ejército de Guatemala. En la primera parte, integrada por tres capítulos, el autor, a través de sus entrevistados sobrevivientes, va analizando detalle a detalle este evento. Uno mira la muerte de los campesinos indígenas y a los verdugos - los oficiales y los pelotones del ejército de Guatemala- desde los ojos de los que van a escapar. Es un relato conmovedor (pp. 5-66). Posteriormente, el libro da un giro en el tiempo y el autor nos lleva hasta 1899 , cuando un coronel hace de aquel territorio - conocido como Paraje Ixquisís - su propiedad privada. Esta historia es contada desde la bitácora del topógrafo Carlos Moreira, quien mide el terreno. El análisis fino con que trabaja el autor le hace interpretar no sólo lo que dice este ingeniero, sino lo que dejó de decir: que en el lugar había gente, propietarios legítimos, pero sin título (pp. 69-75).

Con este fragmento la narrativa logra desnudar cómo a lo largo de la historia se ha configurado la propiedad privada de la tierra. El propietario es el que tiene los títulos: el que tiene los títulos es porque tiene dinero para comprar y medir el terreno. Pero para hacer esto también se necesita poder. Los propietarios, quienes trabajan la tierra, quedan reducidos a meros mozos colonos, si así lo quieren. De esta forma empieza la historia de San Francisco, la comunidad que en 1982 estuvo a punto de desaparecer. Debajo de cada afirmación en esta parte del libro hay un exhaustivo trabajo de archivo.

La trayectoria histórica continúa, ahora desde la mirada de un arqueólogo y antropólogo alemán y su esposa, que hacia inicios de siglo $\mathrm{xx}$ pasaron por aquel territorio. Desde las miradas de esta pareja, Ricardo Falla adentra al lector a la forma de vida de los señores de la tierra en aquella región. En sus diarios, la pareja retrata a estos señores feudales - como ellos les llaman-, las plantaciones, el sistema de tributos y deudas a los que sometían a los campesinos. Una anotación en el diario de la esposa sobre los trajes de las mujeres sirve de pretexto para que el autor haga un análisis de la diferenciación de las condiciones de vida entre los campesinos libres y los mozos colonos (p. 79).

Desde aquel lugar de la periferia, arrinconado en una esquina del mapa de Guatemala, el libro nos hace transitar por los procesos históricos más importantes del siglo xx: la reforma agraria de 1952 (pp. 90-91), la contrarrevolución de 1954 (pp. 91-94), la política agraria de los militares con el Instituto Nacional de Transformación Agraria (INTA) (pp. 94-96), los cambios en la teología católica (pp. 106-108), hasta la llegada del Ejército Guerrillero de los Pobres (EGP) a la zona (pp. 112-124). Estos fragmentos constituyen un excelente ejemplo, para quienes hacemos ciencia social, de cómo articular grandes procesos desde territorios pequeños. La tercera parte del libro nos presenta el trayecto de 1982 a 2010. El relato está tensado por una interrogante: ¿se acabó San Francisco? El autor comienza relatando la huida y la difusión de la noticia sobre la masacre (p. 167), el refugio y la estancia en México (p. 173), el retorno (p. 191), los conflictos por la tierra y el agua (p. 211), la exhumación realizada en 1999 y el entierro de los restos en 2004 (p. 231), el proceso legal en los tribunales (p. 243), el daño psicosocial colectivo (p. 297) y el resarcimiento (p. 315).

A diferencia de otros libros sobre masacres rurales, éste no se 
limita a contarnos el evento y las causas que lo desencadenaron.

Como la vida misma, no todo terminó con la masacre. El texto rastrea qué quedó de la comunidad, qué sucedió mientras los pobladores estuvieron fuera, cómo regresaron y cuál es su situación actual. Es una historia densa que nos muestra con toda claridad la vida de los que debían morir, según las órdenes del ejército. Estos capítulos son un homenaje muy grande a la humanidad de la comunidad de sobrevivientes. Mientras uno va leyendo no deja de estar presente esta idea: que estos hombres, mujeres, niños y ancianos -conforme los planes militaresya no deberían estar. El autor concluye esta parte con varias propuestas acerca del resarcimiento colectivo (p. 353) y la dignificación desde el símbolo (p. 365).

El libro forma parte de un conjunto de trabajos académicos en torno a otras masacres rurales: como Panzós (Grandin, 2007; Sandford, 2009), la región Ixil (Palacios, 2005; Brett, 2007), Rabinal (Tecú, 2006; Suazo, 2009; Del Valle, 2004; Sánchez, [1995] 1997; Sandford, 2003) y el Ixcán (Falla, 1992; Manz, 2010; Brett, 2007), una línea de investigación que se ha desarrollado en torno al genocidio en Guatemala desde la perspectiva de las víctimas. Pero lo que se ha hecho hasta ahora es muy poco en relación con lo que queda por hacer. Hay grandes eventos históricos que siguen sin ser abordados.

$$
\sim
$$

Como balance general, destaco esas aristas en esta obra de Ricardo Falla. Quisiera ahora exponer cinco comentarios que tienen un carácter más general. El primero es que este libro trata sobre la vida y la muerte. Es una historia terrible, pero es la historia de Guatemala. ¿Qué es Guatemala en el contexto de América Latina? O mejor planteado: ¿qué puede ofrecer Guatemala - como caso de investigación- a las ciencias sociales latinoamericanas? Dentro de esa historia se halla la densa historia del genocidio, en la que se entrelazan las perspectivas del campesinado, la emergencia de múltiples movimientos sociales, las elites políticas, económicas y militares, los insurgentes, los pueblos indígenas, los cambios en la economía agrícola, los procesos de industrialización, la estrategia de contrainsurgencia, entre otros. Ésa es nuestra particularidad en el contexto de América Latina: que aquí hubo genocidio -según la Convención de las Naciones Unidas-, en tanto que en los otros países de América Latina, en el contexto de la Guerra Fría, hubo represión. Este libro tiene el gran valor de ir detrás de las grandes preguntas de nuestra historia. Es una antropología que se coloca frente a la realidad y se pregunta por los grandes procesos que mueven la historia y se lanza a buscar explicaciones. Es una antropología que no mira a un lado cuando los traumas de la historia de Guatemala están enfrente.

Pero la historia de Guatemala no sólo es la historia del genocidio y de la muerte. Es también la historia de las luchas de estos campesinos indígenas, de la guerra de los pobres, la guerra de guerrillas; de cómo ésta se articuló con los deseos de cambio de los campesinos indígenas guatemaltecos. Es también la historia de los que escaparon a la maquinaria del ejército de Guatemala, que con su huida ayudaron a cientos - de Yulaurel, la comunidad vecina- a escapar y a vivir: "levántense y salgan", es el grito de don Andrés Paiz García (p. 64). De no haber sido por estos verdaderos ángeles salvadores de la historia, el ejército hubiera continuado la matanza al día siguiente. Por esto es una historia de vida. De vida cuando todo era muerte. Los que estamos aquí, esta noche, celebramos la vida, las vidas que se perdieron, las vidas de los que quedaron, las esperanzas que están con nosotros.

El segundo comentario tiene que ver con la calidad de la investigación. Considero que se ha hecho una tarea excepcional. 
Hay mucho trabajo en la manera en que el autor va detrás de sus fuentes, que sólo es posible si se tiene pasión. La pasión de aquellos que quieren conocer la verdad, para que la verdad sea conocida por otros. El autor sigue con empeño sus fuentes orales, las analiza con agudeza y las coloca en la narrativa como sólo saben hacerlo los orfebres. Va detrás de fuentes de archivo, que cubre de forma exhaustiva. Cada pieza de éstas, por lo que cuesta extraerlas de entre grandes cúmulos de papeles, es valorada como el oro.

El tercer comentario se refiere a las enseñanzas metodológicas que este libro deja para aquellos que quieran aprender a investigar. En realidad uno nunca deja de hacerlo. Cuando se inicia un proyecto siempre hay aprendizajes, pero no todos los días hay encuentros con textos que le den a uno grandes lecciones. Y la mejor forma de aprender a investigar es leyendo los resultados de investigaciones, como la que el autor ha realizado. Una de las lecciones de método es el manejo de las fuentes orales. Las voces de los entrevistados hablan y el autor las presenta en la narrativa. Falla logra eso, que cuesta mucho, que consiste en un balance entre el análisis de uno, como autor, y las voces de los entrevistados. Otra lección de método: estar en el lugar. Es un libro cuyas fuentes han sido recolectadas al ras de los eventos.
Desde septiembre de 1982, cuando el autor escuchó por vez primera el relato de los testigos de la masacre, hasta sus indagaciones más recientes, hay mucho trabajo de campo hecho en Guatemala y México. Quizá "estar en el lugar" sea muy propio de la antropología, pero

lo destaco como una lección de método para otras ciencias sociales. Más allá de lo meramente metodológico, este aspecto tiene implicaciones éticas más profundas, con las relaciones, con los sujetos y con los procesos que se investigan. Otra lección de método: la simpleza. El autor nos recuerda que la responsabilidad de quienes intentamos hacer ciencia social es presentar nuestros hallazgos, los resultados de las investigaciones, de la forma más simple, clara y modesta posible. La sencillez de la profundidad sólo puede basarse en una investigación exhaustiva. Éste es un libro que, a pesar de tratarse de una tragedia humana, se lee bien, porque está redactado de forma sencilla y clara.

Un cuarto comentario sobre este libro es que Ricardo Falla demostró saber hacer uso de la historia. Evitó esa idea muy sociológica o de la ciencia política de que el presente es sinónimo de instantaneidad. Nos descubre cómo uno de los rasgos fundamentales del tipo de campesinado de San Francisco tiene sus orígenes en el siglo XIX, con el despojo y la forma en que los campesinos negocian con el señor su continuidad en la tierra que hasta entonces era de ellos. Pero también permite entender la manera de desplegar miradas hacia el presente. El libro nos da una lección importante de cómo ir más allá del evento central: la masacre, e interesarse por la vida de los sobrevivientes, cómo reconstruyeron su historia con lo que les quedó. Interpreto esta lección no sólo en cuanto al método, sino como una lección de humanidad y como un recurso para devolver la dignidad a las víctimas, a sus familiares, a los sobrevivientes, simplemente contando su historia hasta el presente. Un quinto comentario es que se trata de un estudio consciente de sus limitaciones. Como en otras masacres, una serie de factores se fueron cerrando sobre la comunidad para apuntalar la decisión del alto mando del ejército de Guatemala de enviar tropas a ese lugar con la misión de matar a todos los que se encontraran allí. El autor detalla uno a uno esos factores, en una sucesión histórica. Se presentan, pero también se interpretan, acontecimientos en relación con el resultado final. Aun que hay un punto hasta el que es posible reconstruir las explicaciones con las fuentes de que disponemos hoy. Y hay un momento en que las fuentes se acaban. Lo mejor es decir, como el autor: "hasta allí hemos podido llegar" (p. 124). 
La tarea del investigador consiste en dar coherencia a un proceso complejo, a fin de ofrecer al lector un cuadro más o menos ordenado de personajes, eventos y relaciones. Pero en las circunstancias de una guerra es muy probable que, en vez de orden, uno encuentre interpretaciones parciales, personajes cuyo papel no es fácil de entender, razones yuxtapuestas, causas traslapadas. Esto se evidencia especialmente cuando se tratan de explicar las relaciones entre los campesinos de San Francisco, sus vecinos, los militares, el frente guerrillero Ché Guevara del EgP y el dueño de la finca.

Una de las partes más densas

216 del relato es la que aborda las relaciones entre la comunidad y la guerrilla. El lector percibe cómo la comunidad se divide en sus lealtades, cómo las memorias de unos se transforman desde el presente tendiendo a reinventar sus posiciones políticas. Se trabaja aquí, como ya lo indicaba Ranajit Guha (1999: 256), con un sustrato de rumores que es difícil descifrar. Lo que el autor nos presenta es un relato bien hecho que logra captar la complejidad, muy lejos del "entre dos fuegos" de David Stoll (1993) o de esa idea a lo Yvon Le Bot (1995) de que la teología católica llevó a los campesinos indígenas a la inmolación.

En torno a este punto, el autor logra ir más allá de ese debate sobre la culpa de la guerrilla por empezar una guerra que luego no pudo controlar. Me parece que hay dos elementos que no son fáciles de controlar, máxime cuando los analizamos - no desde el hoy, quieto y previsiblecon los ojos de quien está en medio del tono emocional de una guerra. El primero tiene que ver con el apoyo de parte de la población. Pareciera que en varias localidades de Guatemala -incluso para sorpresa de la propia organización guerrillerael respaldo de las comunidades llegó a grados difíciles de contener. No fueron uno o dos los organizados, sino conglomerados considerables de comunidades. El segundo elemento se refiere a la decisión de los militares guatemaltecos de emprender una campaña como la que llevaron a cabo. ¿Era posible prever lo que no tenía precedentes? Si no se gana, la guerra de guerrillas es sumamente peligrosa, por el papel que las poblaciones juegan en ella. Pero ¿era posible librar esa guerra de otra forma?

Estos dos elementos merecen un análisis que trascienda el estereotipo de la culpa de la guerrilla. Entre las páginas 144 y 145 el autor trasciende esa culpa fácil y ligera - muy sencilla de escribir- y nos presenta una idea más cercana a la realidad. Brinda al lector un relato que angustia, apasiona y deja en qué pensar. El autor se reconoce como parte, en calidad de colaborador con las estrategias de la guerrilla, de la tragedia que a los guatemaltecos nos tocó vivir. Gracias, Ricardo Falla, por haber escrito de nuevo una gran obra para la historia y para las ciencias sociales guatemaltecas. Estoy seguro de que este libro, como los otros que has hecho, será una referencia obligatoria para todo el que quiera entender qué sucedió en Guatemala, cuáles son las raíces del presente que ahora vivimos.

\section{Bibliografía}

Brett, Roddy, 2007, Una guerra sin batallas: del odio, la violencia y el miedo en el Ixcán y el Ixil, 1972-1983, F\&G Editores, Guatemala.

Del Valle, Dora Ruth, 2004, Violencia politica y poder comunitario en Rabinal, Baja Verapaz, Equipo de Estudios Comunitarios y Acción Psicosocial, F\&G Editores, Guatemala.

Falla, Ricardo, 1984, Esa muerte que nos hace vivir. Estudio de la religión popular en Escuintla (Guatemala), ucA Editores, El Salvador. -, 1992, Masacres de la selva. Ixcán, Guatemala (1975-1982), Editorial Universitaria, Guatemala.

— , 1995a, Historia de un gran amor: recuperación autobiográfica de la experiencia con las Comunidades de Población en Resistencia. Ixcán, Guatemala, Editorial Universitaria, Guatemala. , 1995b, Quiché rebelde. Estudio de un movimiento de conversión religiosa rebelde 
a las creencias tradicionales en San Antonio Ilotenango, Quiché (1948-1970), Editorial Universitaria, Guatemala. - 2005, Alicia. Explorando la identidad de una joven maya, Ixcán, Guatemala, Asociación para el Avance de las Ciencias Sociales en Guatemala, Editorial Universitaria, Guatemala.

— 2006, Juventud de una comunidad maya. Ixcán, Guatemala, Asociación para el Avance de las Ciencias Sociales en Guatemala, Editorial Universitaria, Guatemala. -, 2008, Migración transnacional retornada. Juventud indígena de Zacualpa, Asociación para el Avance de las Ciencias Sociales en Guatemala, Editorial Universitaria, Guatemala. _, 2011, Negreaba de zopilotes... Masacre y sobrevivencia: finca San Francisco Nentón, Guatemala (1871 a 2010), Asociación para el Avance de las Ciencias Sociales en Guatemala, Guatemala.
Grandin, Greg, 2007, Panzós: la última masacre colonial, Latinoamérica en la Guerra Fría, Asociación para el Avance de las Ciencias Sociales en Guatemala, Guatemala.

Guha, Ranajit, 1999, Elementary Aspects of Peasant Insurgency in Colonial India, Duke University Press, Londres.

Le Bot, Yvon, 1995, La guerra en tierras mayas. Comunidad, violencia y modernidad en Guatemala (1970-1992), Fondo de Cultura Económica, México.

Manz, Beatriz, 2010, Paraíso en cenizas. Una odisea de valentía, terror y esperanza en Guatemala, Fondo de Cultura Económica, México

Palacios Aragón, Marcio, 2005, Los hilos del genocidio ixil en Guatemala. ¿Cuál paz firme $y$ duradera?, Armar Editores, Guatemala.

Sánchez, Ronaldo, [1995] 1997, Las masacres en Rabinal. Estudio histórico-antropológico de las masacres de Plan de Sánchez,
Chichupac y Río Negro, Guatemala, Equipo de Antropología Forense de Guatemala, Guatemala.

Sandford, Victoria, 2003, Buried Secrets. Truth and Human Rights in Guatemala, Palgrave Macmillan, Nueva York. , 2009, La masacre de Panzós: etnicidad, tierra y violencia en Guatemala, F\&G Editores, Guatemala.

Stoll, David, 1993, Between Two Armies in the Ixil Towns of Guatemala, Columbia University Press, Nueva York.

Suazo, Fernando, 2009, Rabinal, historia de un pueblo maya. Desde el Preclásico hasta la última guerra, Fundación Rigoberta Menchú, Guatemala.

Tecú Osorio, Jesús, 2006, Memoria de las masacres de Río Negro. Recuerdo de mis padres y memoria para mis hijos, Fundación Nueva Esperanza, Rabinal. 